Neurosurg Focus 36 (4):E2, 2014

(C)AANS, 2014

\title{
A brief history of early neuroanesthesia
}

\author{
Srinivas Chivukula, B.S., ${ }^{2}$ Ramesh Grandhi, M.D., ${ }^{1}$ and Robert M. Friedlander, M.D. ${ }^{1}$ \\ ${ }^{1}$ Department of Neurological Surgery, ${ }^{2}$ University of Pittsburgh School of Medicine, Pittsburgh, Pennsylvania
}

\begin{abstract}
Two key discoveries in the 19th century-infection control and the development of general anesthesia-provided an impetus for the rapid advancement of surgery, especially within the field of neurosurgery. Improvements in anesthesia and perioperative care, in particular, fostered the development of meticulous surgical technique conducive to the refinement of neuroanatomical understanding and optimization of neurosurgical procedures and outcomes. Yet, even dating back to the earliest times, some form of anesthesia or perioperative pain management was used during neurosurgical procedures. Despite a few reports on anesthesia published around the time of William Morton's nowfamous public demonstration of ether anesthesia in 1846, relatively little is known or written of early anesthetics in neurosurgery. In the present article the authors discuss the history of anesthesia pertaining to neurosurgical procedures and draw parallels between the refinements and developments in anesthesia care over time with some of the concomitant advances in neurosurgery.
\end{abstract}

(http://thejns.org/doi/abs/10.3171/2014.2.FOCUS13578)

KEY WoRds • neurosurgery $\quad$ anesthesia $\bullet$ history $\bullet$ early $\bullet$ progress

$\mathrm{M}$ ODERN neurosurgery arose in the wake of two great advances in the late 19th century-infection control and the advent of general anesthesia..$^{15}$ The seminal report by Joseph Lister (1827-1912) in 1867 on the concept of antisepsis inarguably challenged the scourge of postoperative infection in surgery; in the years immediately following its publication, mortality rates associated with infection plummeted by as much as $30 \%$ among patients undergoing major surgery. ${ }^{14}$ Equally profound was the popularization of general anesthesia in 1846 in the form of ether vapor brought about at the Massachusetts General Hospital by a demonstration by Dr. William Morton (1819-1868), which paved the way for subsequent advances in neurosurgery (Fig. 1). ${ }^{14,19}$ Yet, even in the earliest times, some form of anesthesia or perioperative pain management was in use during neurosurgical procedures, especially craniotomies. ${ }^{2}$ Much has been written about neuroanesthesia in the years since 1846 , but relatively little documentation exists of neurosurgical anesthesia in earlier ages. ${ }^{6,10,26}$ The following is a brief description of the substances and techniques used in early neuroanesthesia until the discovery of ether and chloroform in the 19th century. Because no history of neuroanesthesia can be told without the associated surgical context (and vice versa), we also discuss the relevant neurosurgical advances that paralleled the refinements and developments in anesthesia over the ages.

\section{Antiquity}

Since the first reported discovery of trephined Neolithic skulls in 1873 at Lozère (France), substantial ar- chaeological evidence has established the veracity of early trephination, dating the first craniotomies to as far back as the Paleolithic period. ${ }^{10,21}$ In most instances, the trephination was solitary, but multiple defects have also been discovered (the record is seven in a single patient) in a wide variety of shapes and sizes..$^{21}$ It was not uncommon for the trephination to cross suture lines and/or the sagittal sinus. The motivation for the craniotomies is contested; supported by the occasional discovery of fracture lines in some trephined skulls, some independent theorists have postulated that the surgery was done for therapeutic purposes. A popular belief among many historians is that the openings were made to alleviate pain or to allow the escape of demons, spirits, and supernatural elements from the head; many primitive cultures considered these to be the underlying cause of "pathologies" manifesting as headaches, insanity, or convulsions. ${ }^{25}$ The Peruvian archaeologist Julio Tello (1880-1947) even wrote that the openings may have been done for organic diseases, osteomyelitis, syphilitic caries of the skull, and so on, although there is little evidence to support this view. ${ }^{28}$

With the primitive equipment and crude instruments used in those early days, it has been estimated that each hole may have taken at least half an hour of surgical time. Devoid of modern anesthetic agents or techniques, the exact means used for pain management and/or sedation during the procedures are unknown. ${ }^{4,10}$ Descriptions of the pain-relieving properties of coca leaves in early Peruvian literature has led to speculation that coca leaves may have been used. Daturas have also been frequently described, leading to hypotheses that their narcotic properties were known to the medicine men of those ages and used as 


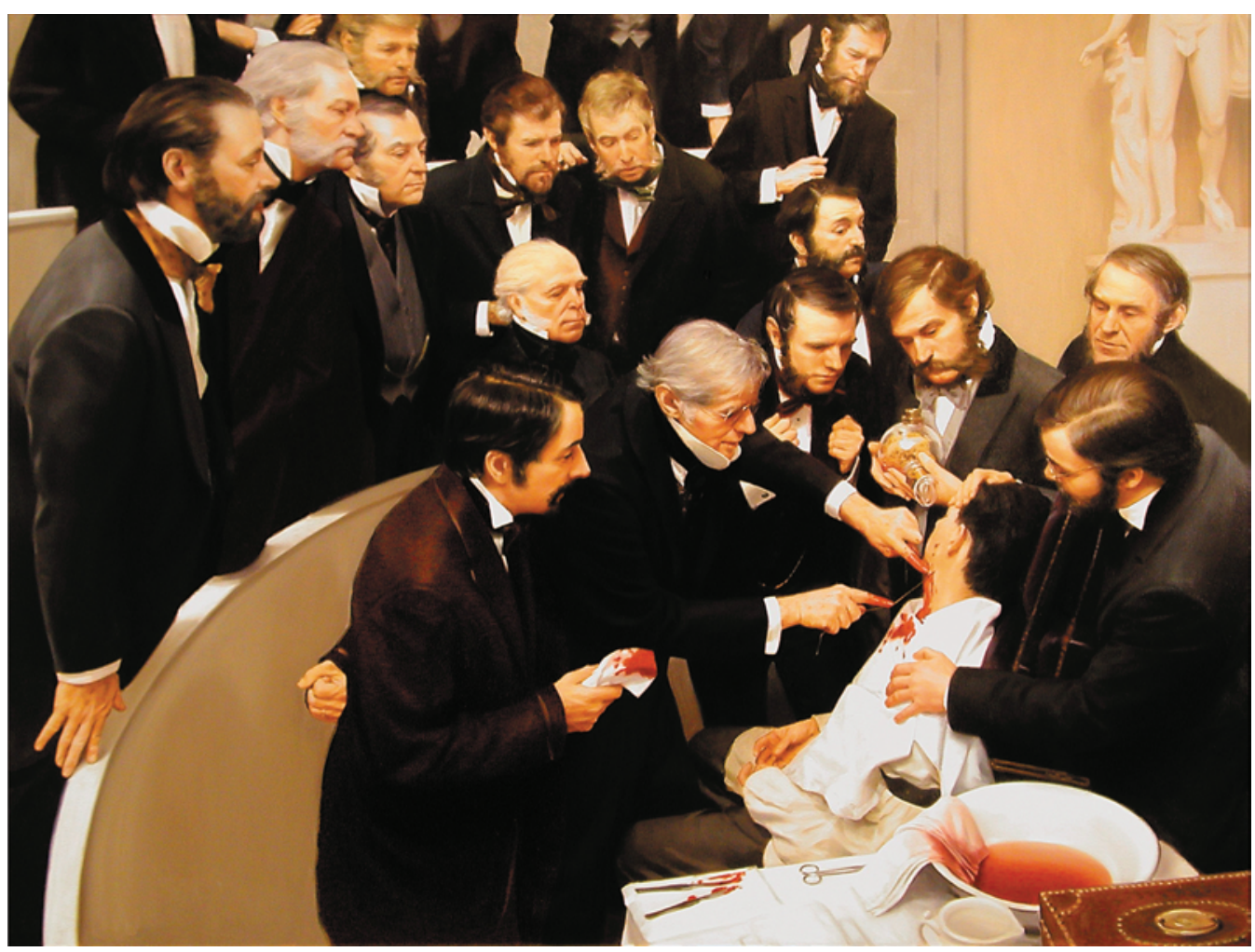

FIG. 1. Removal of a head and neck tumor by Dr. John C. Warren from a patient, Edward G. Abbott, under the influence of ether anesthesia in the "Ether Dome" amphitheater at the Massachusetts General Hospital on October 16, 1846. William T. G. Morton, at whose request the public demonstration was arranged, is seen holding the anesthesia-delivery apparatus behind and to the patient's right. The painting is entitled "Ether Day 1846" and was created in 2000 by artists Warren and Lucia Prosperi. Reprinted courtesy of Massachusetts General Hospital.

anesthetics. It is noteworthy that the narrow gouge that seems to have been used in most instances of these early trephination procedures indicates that the patients were largely kept free from the fear of pain. Based on descriptions of ancient medical records from South America, early anesthetists may have been employed to chew coca leaves and spit into wounds to create an environment of local anesthesia. ${ }^{4,10}$

The Greco-Roman period saw a flourish of civilization in the islands of the Mediterranean Sea and, with it, a vigorous interest in medicine and surgery. ${ }^{26}$ The Greek physician Hippocrates (460-370 BC) described trephination for several pathologies of the central nervous system performed in ancient Greece; Greek surgeons and physicians appear to have had a fairly accurate, albeit primitive, understanding of neurology. ${ }^{12}$ In describing seizures, Hippocrates wrote "for the most part, convulsions seize the other side of the body." ${ }^{26}$ He noted that severe cranial traumas were universally fatal: "[the individuals] die before the end of seven days in the summer, and before fourteen, if in winter." 10,26 His mention that blood under the cranium could be removed by perforating the skull indicates a familiarity with epidural and subdural hematomas. Despite the rather advanced neurosurgical and neuroanatomical knowledge for the times that appears to have existed, inferred from Hippocrates' writings, the ancient Greeks' use and understanding of neuroanesthesia do not appear to have differed much from those of fellow practitioners elsewhere. Hippocrates describes the use of linen dressings soaked in wine for their soporific effects in analgesia.

This epoch was notable for perhaps the earliest written record of the prescription of botanical products for pain relief. In the text De material medica by Dioscorides (40-90 AD), a Greek physician, pharmacologist, and botanist, the narcotic effects of mandrake, henbane, and opium, as well as the effects of alcohol, were meticulously detailed..$^{18}$ Dioscorides described the use of laudanum, a tincture containing approximately $10 \%$ opium by weight. Although disputed, he may have been the first to coin the term "anesthesia"15 and may also have been the first to recognize that pressure on the carotid artery could induce a state of insensibility; indeed, the Greek word for carotid artery means "the artery of sleep." " However, the use of these products for pain relief was not widespread among surgeons of the time; a general disbelief regarding the need for anesthesia persisted for several hundreds of years to come. This concept of anesthesia being unnecessary was illustrated in the writings of Aretaeus of Cappadocia, a physician from the 2 nd century AD, who performed surgeries for the treatment of seizures by perforating the skull with a trephine and noted that anesthesia was not needed, as "the habit of such persons renders them tolerant of pains and their goodness of spirits and good hopes render them strong in endurance."1 


\section{Middle Ages and the Renaissance}

Progress in neurosurgery slowed considerably with the fall of the Roman Empire. ${ }^{10,22}$ The Roman Catholic church became very influential in medical care, and the art of surgery began to decline. In $1163 \mathrm{AD}$, the church laid down an edict: "Ecclesia abhorret a sanguine" (literally, "the Church detests blood"). There were restrictions placed on the use of human bodies in anatomical studies, and progress in the field and practice of surgery was therefore stunted. Medical advancement in Europe consequently slowed, but physicians in other parts of the world continued their medical and/or surgical practices. At the beginning of the 10th century AD, Muhammad ibn Zakariya al-Razi (also known as Rhazes; 865-925 AD) compiled the Liber Continens - a compendium of all literature and knowledge belonging to the Arab world including medicine, philosophy, religion, mathematics, and astronomy. Among several important observations he made within this work, one was particularly remarkable: he wrote that pressure on the brain, rather than the presence of a skull fracture itself, was the more important factor in determining the prognosis after head injuries. ${ }^{6}$

Despite Rhazes' impressive accomplishment, it was not until later in the 10th century, with the establishment of a medical school at Salerno (in modern-day Italy), that the knowledge from several hundred years prior was truly brought to the fore, reviving European medicine. Constantinus Africanus (1017-1087) arrived at the school in Salerno, bringing with him Arabian medical manuscripts patterned after the teachings of ancient Greek and Roman physicians. This contributed greatly to the dissemination of important medical knowledge across Europe beginning in the 11th and 12th centuries AD. Aided by the Renaissance movement, the Catholic church's stance on surgery began to change. ${ }^{22}$ Despite the shift in thought and culture, anesthesia continued to remain infrequently addressed in new medical literature in Europe. While the church had come around to view surgery as inevitable and necessary at times, the popular religious notion was that pain was a "noble" state; for instance, the Catholic church claimed that pain served God's purpose and alleviation was not to be attempted. ${ }^{23}$

When anesthesia was used, "narcosis" was achieved mainly by utilizing the same substances that were applied centuries before by Aretaeus; cannabis indica, henbane, opium, wine, and mandrake were most popular among European surgeons., ${ }^{1,22}$ The era of the Middle Ages did result in the use of a novel means for achieving sedation: the soporific sponge. Depending on the surgeon and/or locale of practice, various combinations of opium, mandrake, and hemlock were used. ${ }^{22}$ Theodoric Borgognoni (1205-1298), for instance, mixed opium with $1 \mathrm{oz}$ each of mulberry, hyosciamus, juice of hemlock, leaves of mandragora, and the juice of woody ivy and let the ingredients be absorbed by a new sponge. The sponge was placed in hot water for an hour and then applied to the patient's nostrils. ${ }^{10,22,23,26}$ In contrast, Hieronymus Brunschwig (1450-1512) had patients drink a narcotic potion containing scopolamine, ${ }^{18}$ a practice considered dangerous by other physicians who worried that the effects of the oral narcotic concoction were harder to regulate than those delivered by an inhalational route via a sponge. ${ }^{22}$

Both mandrake and henbane are mild narcotics containing belladonna alkaloids (the modern-day medicines atropine and scopolamine are derived from mandrake and henbane, respectively). ${ }^{2,25}$ It is suspected that wine was added to the sponge bath during boiling to enhance its sedative power. ${ }^{10}$ The physicians of Myddvai, herbalists from Wales, further advised that to improve anesthetic efficacy, "when you are prepared to operate upon the patient, direct that he shall avoid sleep as long as he can, and then let some of the potion be poured into his nostrils, and he will sleep without fail." 26

The first accounts of not only inducing anesthesia but also of reversing sedation surfaced around the time of the Middle Ages. In a book titled A History of Neurological Surgery, edited by Dr. A. Earl Walker, the authors write of two surgeon brothers in Hindustan who performed a craniotomy in 927 AD to remove an unspecified, unidentified tumor from the brain of the King of Dhar (Dhar is in modern-day India). The brothers induced anesthesia with a drug recorded in Sanskrit writings as "samohine," trephined the skull, and removed the tumor. ${ }^{26}$ Upon completion of the case, the anesthesia was reversed by pouring an onion compounded with vinegar into the king's mouth. ${ }^{10,26}$ Accounts from Sanskrit writings of similar surgeries in a few other patients suggest that soporific sponges were also popular in Southern Asian neurological surgery of the times.

Numerous adjuvant agents-both topical and for ingestion-were additionally administered to patients who underwent craniotomies during the Middle Ages in Europe, with the hope that these adjuncts would lead to better outcomes. ${ }^{2}$ Some were quite remarkable for their unique ingredients. Ambroise Paré (1510-1590), a French surgeon, described a concoction that he was informed of by an Italian surgical colleague; it was composed of a mixture of newly whelped puppies boiled in an oil of lilies and earthworms and prepared in turpentine of Venice. ${ }^{10}$ Similarly, in 1694, a German wound surgeon named Matthäuss Purmann (1649-1711) recommended the application of salves made of earthworms, hog brain, mummy, and "the moss of a man's skull that was either killed or hanged, and gathered when the star of Venus predominates" to patients with cranial wounds., ${ }^{2,5,22,23}$ Owing to the belief that it had cleansing properties, rose oil was frequently used on the wound itself and also as an agent to lubricate and soak surgical instruments and dressings. The recipe of the preparation varied according to surgeon preference. Paré applied a mixture of rose oil, egg yolk, and turpentine; he believed it necessary to maintain the temperature of the preparation and, to this end, noted the necessity to dilute the mixture with cold water in warm weather and vice versa for optimal wound healing. ${ }^{2}$

Earlier on in the Middle Ages, anatomical dissection of the deceased and autopsies were mostly forbidden across the globe, impeding progress in the anatomical and physiological understanding of the central nervous system, which consequently limited progress in anesthesia as well. This gradually changed, especially toward the later part of the 14th century, following which time, 


\section{S. Chivukula, R. Grandhi, and R. M. Friedlander}

several important advances were made. Andreas Vesalius (1514-1564) provided detailed descriptions of the internal anatomy of the brain and the ventricular system. Gabriele Falloppio (1523-1562) wrote elegantly of the trigeminal, auditory, glossopharyngeal, and chorda tympani nerves; Bartolomeo Eustachi (1514-1574) identified the abducens and the optic nerves, and Willis identified patterns within the intracranial vascular system. ${ }^{26}$

One of the first medical texts in English, titled The Physician's Practice, was written during the Renaissance period. This book, published in 1639, expounded on headaches, palsies, paralyses, brain inflammations, and other diseases and provided details on their potential causes. ${ }^{5}$ Although the book itself did not recommend surgery, going as far as to say "if a chirurgeon, there also you may been furnished with Powders, Oyntments and Emplasters, without which a man cannot excel in the art of Chirurgery," it was a harbinger of great discoveries that would be made in neurophysiology in the near future. ${ }^{5}$ In 1765, Domenico Cotugno (1736-1822) wrote on the cerebrospinal fluid; in the early 19 th century, François Magendie (1783-1855) expounded further on the nature and the role of the cerebrospinal fluid and the principles of cerebral physiology. All of these would prove invaluable in the later understanding of neuroanesthesia, especially the effects of anesthetics on the central nervous system. ${ }^{7}$

\section{The "Discovery"}

The dramatic improvement in anesthetics over the course of the 19th century was perhaps the biggest driving force for the advances in neurosurgery that followed. Carbon dioxide, hydrogen, and nitrogen were discovered toward the end of the 18th century and set off a new era of exploration and experimentation with the properties and uses of various chemicals, including oxygen and nitrous oxide. ${ }^{20}$ Sir Humphry Davy (1778-1829), who established the Pneumatic Institute in Bristol, England, in 1799, and is known to have been one of many at the time who inhaled nitrous oxide and ether for pleasure, suggested that these gases had the ability to relieve the pain of surgical operations. $^{24}$

However, the relatively slow implementation of anesthesia in neurosurgery had to do with the prevailing reluctance of surgeons of the era to perform cranial operations; indeed, Sir Astley Cooper (1768-1841), consulting surgeon to Guy's Hospital in London, England, published a series of lectures on the practice and principles of surgery in 1829, reporting that "trephining in concussion is now so completely abandoned that in the last four years I do not know that I have performed it once, whilst 35 years ago I would have performed it five or six times a year." Rather than trephine, Cooper's recommendation was instead to use leech therapy to the temporal arteries, calomel purging, and frequent venesection. ${ }^{10}$ Any anesthesia necessary was achieved with liberal quantities of wine. ${ }^{2,6}$ Even in 1869, Dr. John Erichsen (1818-1896) of the University College Hospital in London wrote of anesthesia in neurosurgical trauma: "in the treatment of injuries of the brain, little can be done after the system has rallied from the shock, beyond attention to strict antiphlogistic treatment, though this need not be of a very active kind. As much should be left to nature as possible, the surgeon merely removing all sources of irritation and excitement from his patient and applying simple local dressings." 22,23

At the beginning of the 19th century, if relaxation was desired, the patient might be intoxicated with alcohol or drugged with opium. Sir Humphry Davy, though, noted that nitrous oxide could produce a state of insensibility. ${ }^{3,8}$ Wells, a dentist of Hartford, Connecticut, in 1844, experimented with nitrous oxide on several patients in quick succession but stopped abruptly when one of his patients succumbed to the toxicity of the gas and died. This anecdote, relayed to his close friend and colleague William Morton, became the inspiration for Morton's own experimentation with anesthetic agents. ${ }^{27}$

Although William Morton popularized the use of ether as an anesthetic agent, the credit for its initial use in the surgical setting belongs to another American physician, Dr. Crawford W. Long (1815-1878). On March 30, 1842 , Long removed a small tumor from the neck of a patient, who noted that he was amnestic to the events of the surgery; Long, however, did not publish his results until much after Morton's public demonstration of ether anesthesia on October 16, 1846, at the Massachusetts General Hospital, ${ }^{17}$ when Dr. John C. Warren (1778-1856) removed a vascular tumor from the submaxillary region in a patient anesthetized with sulphuric ether. Although the use of ether and chloroform as modern-day anesthetics quickly became routine the world over, its implementation in neurosurgery only came several decades later.

At the turn of the 20th century, there were great debates regarding the relative merits of chloroform and ether. Victor Horsley (1857-1916) performed a series of experiments in animals from 1883 to 1885 and concluded that, although ether was safer, it was not to be recommended in favor of chloroform because it produced a rise in blood pressure and an increase in blood viscosity, with a consequent potential for hemorrhage. ${ }^{13}$ Additionally, because morphine constricted blood vessels, he suggested that a combined morphine and chloroform narcosis be used. Of note, however, he later recommended abandoning the use of morphine when its depressant effect on the respiratory center became widely recognized. ${ }^{13,26}$ The anesthesia preferences of many of the pioneers in neurosurgery varied: Fedor Krause (1857-1937) used chloroform alone, while Emil Theodor Kocher (1841-1917) hesitated to do so because of its tendency to lower the blood pressure..$^{11,16}$ Harvey Cushing (1869-1939), on the other hand, was impressed with chloroform's efficacy but preferred a cautious approach to anesthesia, favoring ether and restricting his use of chloroform to children. He frequently employed ethyl chloride in inducing the first stage of anesthesia and may well have been the first to introduce the concept of induction in anesthesia. ${ }^{26}$

Around the same time, the use of local anesthesia gained prominence. Cocaine had been formally discovered in 1860 and was introduced into surgery in 1884. Use of procaine, which was first synthesized in 1905, immediately became commonplace among surgical anesthetics. Most neurosurgeons used local infiltration anesthesia for select cases, but beginning in 1913 with its populariza- 
tion by de Martel, it became a common practice to use it for all craniotomies. By 1917, Harvey Cushing recommended the use of local anesthesia for all neurosurgical cases. $^{26}$ The field of anesthesia quickly began to develop and by the time World War II, several agents had come into routine use, including tribromoethanol and pentothal sodium. Anesthesia as a specialty grew exponentially in the years that followed.

\section{Conclusions}

The evolution of anesthetics and perioperative care from prehistoric times to modern day offers a fantastic perspective on the advances of medicine and patientcentered improvements in comfort and delivery of medical care. Although neurosurgical procedures have been performed since prehistoric times, the greatest advances in neurosurgical understanding and operative outcomes were achieved relatively recently, coincident with improvements in anesthetic care. The contribution of anesthesia to the development in neurosurgery has been of paramount importance, radically altering the field as we know it today.

\section{Disclosure}

The authors report no conflict of interest concerning the materials or methods used in this study or the findings specified in this paper. The authors additionally have no vested interest in the publication of any portion of this manuscript.

Author contributions to the study and manuscript preparation include the following. Conception and design: Chivukula, Grandhi. Drafting the article: all authors. Critically revising the article: all authors. Reviewed submitted version of manuscript: all authors. Study supervision: Friedlander.

\section{References}

1. Aretaeus: The Extant Works of Aretaues, the Cappadocian. Adams F (trans). London: Sydenham Society, 1856, pp 469-483

2. Bakay L: An Early History of Craniotomy: From Antiquity to the Napoleonic Era. Springfield, IL: Charles C Thomas, 1985, pp 7-10

3. Bigelow HJ: Insensibility during surgical operations produced by inhalation. Boston Med Surg J 35:309-317, 1846

4. Broca P: Sur les trépanations préhistoriques. Bull Mem Soc Anthropol Paris 25:542-557, 1874

5. Bruel W: Praxis Medicinae. London: John Norton, 1639

6. Cooper A: Lectures on the Principles and Practice of Surgery. London: Westley, 1829

7. Cotugno D: De Ischiade Nervosa Commentarius. Naples: Simoniana, 1762

8. Davy H: Researches, Chemical and Philosophical, Chiefly Concerning Nitrous Oxide, or Dephlogisticated Nitrous Air, and Its Respiration. London: J Johnson, 1800
9. Dioscorides Pedanius: The Greek Herbal of Dioscorides. Gunther RT (trans). Oxford: Oxford University Press, 1934

10. Frost EAM: A history of neuroanesthesia, in Eger E, Saidman LJ, Westhope RN (eds): The Wondrous Story of Anesthesia. New York: Springer, 2014, pp 871-885

11. Hartley F, Kenyon JH: Experiences in cerebral surgery. Ann Surg 45:481-530, 1907

12. Hippocrates: On injuries of the head, in: The Genuine Works of Hippocrates. Adams F (trans). London: Sydenham Society, 1849 , pp 421-466

13. Horsley V: On the technique of operations on the central nervous system. BMJ 2:411-423, 1906

14. Horwitz NH: The history of the operating room, in Apuzzo MLJ (ed): The Operating Room for the 21st Century. Rolling Meadows, IL: American Association of Neurological Surgeons, 2003, pp 6-9

15. Kerr PB, Caputy AJ, Horwitz NH: A history of cerebral localization. Neurosurg Focus 18(4):E1, 2005

16. Krause F: Surgery of the Brain and Spinal Cord Based on Personal Experiences. New York: Rebman Co, 1912

17. Long CW: An account of the first use of sulphuric ether by inhalation as an anaesthetic in surgical operations. South Med Surg J 5:705-713, 1849

18. Nuland SB: The Origins of Anesthesia. Birmingham, AL: Classics of Medicine, 1983, pp 8-83

19. Paget S: Sir Victor Horsley: A Study of His Life and Work. London: Constable, 1919, pp 90-112

20. Priestley J: Experiments and Observations on Different Kinds of Air. London: Thomas Pearson, 1790

21. Prunières PB: Sur les crânes artificiellement perforés à l'époque des dolmens. Bull Mem Soc Anthropol Paris 9:185-205, 1874

22. Raper HR: Man Against Pain: The Epic of Anesthesia. New York: Prentice-Hall, 1945, p 8

23. Robinson V: Victory Over Pain: A History of Anesthesia. New York: Henry Schumann, 1946, p 29

24. Taylor FL: Crawford W. Long and the Discovery of Ether Anesthesia. New York: Paul B Hoeber, 1928

25. Wakefield EG, Dellinger SC: Possible reasons for trephining the skull in the past. Ciba Symp 1:166-169, 1939

26. Walker AE: A History of Neurological Surgery. New York: Hafner, 1967

27. Wells H: A History of the Discovery of the Application of Nitrous Oxide Gas, Ether and Other Vapors to Surgical Operations. Hartford, CT: JG Wells, 1847

28. Williams HU: Human paleopathology with some original observations on symmetrical osteoporosis of the skull. Arch Pathol 7:839-902, 1929

Manuscript submitted December 17, 2013.

Accepted February 11, 2014.

Please include this information when citing this paper: DOI: 10.3171/2014.2.FOCUS13578.

Address correspondence to: Robert M. Friedlander, M.D., Department of Neurological Surgery, University of Pittsburgh Medical Center, PUH Ste. B-400, 200 Lothrop St., Pittsburgh, PA 15213. email: friedlanderr@upmc.edu. 